\title{
Effect of emotional intelligence and resilience on trauma coping among university students
}

\begin{abstract}
BACKGROUND
Exposure to natural or manmade disasters is associated with long-term health consequences, including those for mental health. Trauma can be considered as the severe mental health outcome of such kinds of disasters. University students as an academic population can also be exposed to different types of disasters in their life. However, most students tend to remain within the academic society due to their coping capacities. It is possible that some students who are suffering from a trauma may not have been identified and that some may even have healed due to individual resilience.
\end{abstract}

PARTICIPANTS AND PROCEDURE

This study investigated samples of German and Sri Lankan university students $(N=356)$, attempting to identify re- lationships between emotional intelligence and its impact on trauma compared with resilience capacities. A purposeful sampling method was used for data collection.

\section{RESULTS AND CONCLUSIONS}

Independent sample $t$-test and hierarchical multiple regression analysis demonstrated that German students and Sri Lankan students used different levels of resilience capacity and emotional intelligence in their trauma coping.

\section{KEY WORDS}

trauma; emotional intelligence; resilience; approach coping; avoidance coping

ORGANIZATION - 1: Department of Educational and Rehabilitative Psychology, Institute of Psychology, University of Leipzig, Germany · 2: Department of Clinical Psychology, Institute of Psychology, University of Leipzig, Germany AUthors' Contributions - A: Study design - B: Data collection - C: Statistical analysis - D: Data interpretation . E: Manuscript preparation · F: Literature search · G: Funds collection CORRESPONDIng AUthor - Asanka Bulathwatta, Ph.D., University of Leipzig, Institute of Psychology, Educational and Rehabilitative Psychology, Neumarkt 9-19, 04109 Leipzig, Germany, e-mail: asankabulathwatta@gmail.com 


\section{BACKGROUND}

The general question of this study is to explore how emotional capacity (emotional intelligence) and recovery capacity (resilience) can influence coping processes in university students after traumatic experiences. The cross-cultural format (Germany vs. Sri Lanka) of the study was chosen in order to compare a German sample which was expected to experience lower numbers of traumatic experiences and a Sri Lankan sample that was expected to report high traumatic experiences regarding the ways in which both samples react to trauma.

Identifying students who have had traumatic experiences is greatly needed in order to facilitate their academic achievements and social life at the university. Therefore, university students in late adolescence will be selected as a sample of this study as they are able to understand and follow some research guidelines and questionnaires in an efficient manner that leads to obtaining higher validity and reliability of the research outcome (Bulathwatta, 2013).

\section{TRAUMATIC EVENTS, EMOTIONAL INTELLIGENCE, RESILIENCE AND COPING}

DSM-5 defines a trauma or traumatic event as an 'experience that causes physical, emotional and psychological distress or harm'. Moreover, DSM-5 points out that there are different types of traumatic events, namely, natural disasters (hurricane, flood, tornado), industrial disasters, accidents (car, train, etc.), childhood sexual abuse, rape, criminal victimization or domestic violence. In addition to that, there are other stressors which can leave individuals traumatized, such as job loss, financial difficulties, problems with bill collectors, marital problems, serious illness of household members, and death of a family member or close friend (American Psychiatric Association, 2013).

The influence of traumatic events on affected people and their reactions differ from person to person and from region to region. Therefore, trauma has been defined as a stress event that presents extraordinary challenges to coping and adaptation (Agaibi \& Wilson, 2005). According to Pynoos (1993), trauma can be considered as a contextually defined phenomenon. Moreover, it can encompass a range of events that overwhelm an individual's coping capacities and involve threats of serious injury or death to the self or someone close to the individual (Banyard \& Cantor, 2004).

As SAMHSA (2014) points out, the term "trauma" refers to experiences that cause intense physical and psychological stress reactions. It can refer to a single event, multiple events, or a set of circumstances that is experienced by an individual as physically and emotionally harmful or threatening and that has lasting adverse effects on the individual's physical, social, emotional, or spiritual wellbeing.

Trauma can vary in its nature. In the review of Wilson and Raphael (1993) regarding war trauma, natural and technological disasters, torture, the holocaust, and duty-related trauma, the authors identified seven factors associated with trauma-related resilience capacity: (a) locus of control (i.e., a sense of efficacy and determination), (b) self-disclosure of the traumatic experience to significance others, (c) a sense of group identity and sense of self as a positive survivor, (d) the perception of personal and social resources to aid in coping in the post-trauma recovery environment, (e) altruistic or pro-social behaviors, (f) the capacity to find meaning in the traumatic experience and life afterward, and $(\mathrm{g})$ connection, bonding, and social interaction within a significant community of friends and fellow survivors.

On the basis of high vulnerability to trauma, posttraumatic stress disorder (PTSD) can develop. PTSD has been described as an anxiety disorder which develops usually as a response to an overwhelmingly terrifying, often life-threatening event by McNally (2006) and as a trauma and stress-related disorder by the DSM- 5 .

Several studies have examined the prevalence of traumatic experience and post-traumatic stress reactions in samples of youth and adults. In the National Comorbidity Survey (NCS), Perkonigg, Kessler, Storz, and Wittchen (2000) reported that $60.70 \%$ of American males and $51.20 \%$ of females aged fifteen to twenty-four reported exposures to one or more traumatic events (Friedman et al., 2011).

Lis-Turlejska (2008) described the prevalence of traumatic events and posttraumatic symptoms among university level students in Poland. The study was conducted with 475 students (69\% women, $30 \%$ men, $M=22.90$ years). The results of the study indicated that a majority of the sample had experienced traumatic events, with $75.60 \%$ having experienced at least one potentially traumatic event.

Vrana and Lauterbach (1994) examined the prevalence of traumatic events and post-traumatic psychological symptoms in a non-clinical sample of college students. This study was conducted with 440 undergraduate students. Among those, $84 \%$ of the subjects reported experiencing at least one event of sufficient intensity to potentially elicit post-traumatic stress disorder. One third of the sample had experienced four or more traumatic events.

Most of the victims who are affected by traumatic events show numerous emotional disturbances and damage resulting in drastic life changes. Among the most prevalent symptoms of traumatic events are behavioral and mood changes, sleeplessness, loss of appetite and emptiness of facial expressions. However, the underlying emotions that cause the superficial reactions that can be observed are not easily revealed. Therefore, understanding patients' emotions and us-
Emotional intelligence and resilience: effect on trauma coping 
ing their emotional status in order to facilitate reliable coping strategies is essential (Bulathwatta, 2013).

\section{TRAIT EMOTIONAL INTELLIGENCE}

The present study was designed to explore the role of emotional intelligence in the development of coping with traumatic experiences. Hereby, university students were seen as a specific population having some specific issues and emotional reactions. For example, many students have problems related to partnership issues and sexual behaviors and the affections related to these (Lewis, Granato, Blayney, Lostutter, \& Kilmer, 2012). Furthermore, according to Gerdes and Mallinckrodt (1994), academic achievements and academic standings give students more emotional problems related to social adjustments.

The present study used the concept of trait emotional intelligence (EI) by Petrides, Frederickson, and Furnham (2004). According to Petrides et al. (2004) trait EI (which is understood as emotional self-efficacy) refers to a constellation of behavioral dispositions and self-perceptions concerning one's ability to recognize, process, and utilize emotionally laden information. The effect trait EI has on scholastic achievement tends to be more pronounced in vulnerable groups (e.g., low ability, maladjusted, learning-disabled). This is because vulnerable or disadvantaged individuals are more likely to experience stress and emotional difficulties during the course of their studies and, consequently, are more likely to benefit from an adaptive disposition to deal with such difficulties.

Trait EI (emotional self-efficacy sensu Petrides et al., 2004) differs from the model of emotional intelligence introduced by Mayer and Salovey (1997). They defined emotional intelligence as the ability of a person to perceive something accurately, to appraise, to express emotions, to access and/or generate feelings, to understand emotions and have emotional knowledge as well as to regulate emotions to promote emotional and intellectual growth (Mayer \& Salovey, 1997).

\section{RESILIENCE AND TRAUMA COPING}

In addition, resilience is a key factor of health in general, but it can also be a key factor for coping with loss, a traumatic situation, etc. It can be defined as an emotional elasticity for coping. Most people are exposed to at least one violent or life-threatening situation during the course of their life. As human beings, we have to experience sorrowful situations such as death of close friends and relatives. But not everybody copes with these potentially disturbing events in the same way. Some people experience acute distress from which they are unable to recover. Others suffer less intensely and for a much shorter period of time. Resilience seems to be an important key factor to determine that kind of emotional stability within these situations (Bonanno, 2004).

According to Walker (2005), both resilience and recovery are prominent factors during the process of traumatic experience that may impact the development of emotional or mental illnesses as well as the strength of traumatic effects. The Prince-Embury Scale of Resilience (2007) consists of three sub-scales: Sense of Mastery, Sense of Relatedness, and Emotional Reactivity. For the purpose of this research, only Sense of Mastery and Emotional Reactivity were selected as the sub-factors as Sense of Relatedness was not directly related to the research background. The Emotional Reactivity skill is an important factor in determining someone's resilience capacity. Likewise, children develop the Sense of Mastery (self efficacy) during childhood, and children learn Emotional Reactivity. Pathological development of one's life and the vulnerability and difficulties faced by human beings generate emotional reactions pertaining to them (Prince-Embury, 2007).

\section{DIFFERENCES OF TRAUMA BETWEEN COUNTRIES}

There are differences in the prevalence of psychological trauma between various countries. Developing countries have higher prevalence of trauma compared to developed countries. But within developed countries there are variations of traumatic events based on regions. For example, in South Africa, PTSD may emerge through severe violence in public spaces. In Japan, Spain and Northern Ireland PTSD is common after sexual and physical violence. According to a European survey, sexual violence and war events were associated with the longest duration of symptoms (Atwoli, Stein, Koenen, \& McLaughlin, 2015).

\section{THE PRESENT STUDY}

This study aims to explore the role of emotional intelligence and resilience in the development of coping strategies for traumatic events among university students. The study used a purposeful sampling method and assumed that there are cross-cultural differences in students' self-reports of emotional intelligence and resilience. Germany and Sri Lanka have two different cultural patterns. Germany is a highly individualistic country, whereas Sri Lanka represents highly collectivistic cultural patterns (The Hofstede Center, 2015). According to the report made by the Hofstede Center in 2015, Sri Lanka has low values in terms of power distance, masculinity, uncertainty avoidance, long-term orientation and indulgence compared to Germany. 


\section{PARTICIPANTS AND PROCEDURE}

\section{MEASURES}

Traumatic experiences. The effects of experienced traumatic events were assessed with the Essener Trauma-Inventory (ETI). The ETI is based on DSMIV and is a trauma assessment tool developed also for the assessment of young people (Tagay, Düllmann, \& Senf, 2004). In the current study, the first part of the questionnaire was used to identify the disasters that people faced in their life (i.e. natural disaster or other traumatic events, $\alpha=.54$ ) and a second part is based on the most disastrous events among the traumatic events they faced as well as psychological symptoms occurring during the past three months such as Intrusion (i.e., Did the event cause upsetting thoughts or images that came to your mind although you didn't want them to?, $\alpha=.77$ ), Avoidance (i.e., Have you tried not to think about the event, not to talk about it or to suppress feelings about it?, $\alpha=.77$ ), Hyperactivity (i.e., Did you have trouble falling or staying asleep?, $\alpha=.72$ ), Dissociation (i.e., Did you have moments in which you lost track of what was happening or did you feel like not being a part of what was going on?, $\alpha=.75$ ).

Emotional intelligence. The "Trait Emotional Intelligence Scale" was developed by Petrides (2010). It has four subscales: wellbeing, self-control, emotionality and sociability. The scale is a 1-7 Likert scale for which negative items are reversed with the index proposed by the author of the scale (Petrides et al., 2004).

Examples for the subscale are Wellbeing (i.e., I generally don't find life enjoyable, $\alpha=.90)$, Self-Control (i.e., I usually find it difficult to regulate my emotions, $\alpha=$.66), Emotionality (i.e., Expressing my emotions with words is not a problem for me, $\alpha=.82$ ) and Sociability (i.e., I can deal effectively with people, $\alpha=.70$ ).

Resilience. Students' resilience capacity was assessed with the help of the Resilience Scale for Children and Adolescents developed by Prince-Embury (2007). It was a best fit measurement to the research as we considered the late adolescence period of the participants. The scale has three subscales. In this study we used only the Sense of Mastery sub-scale and the Emotional Reactivity sub-scale. 'Sense of mastery' refers to a sense of having control over the forces that affect one's life; 'emotional reactions' refers to basic reactions that can be used as resilience capacity. Each subscale consisted of 20 items. Examples for the sub-scales are Sense of Mastery (i.e., I can make good things happen, $\alpha=.87$ ) and Emotional Reactivity (i.e., If I am angry, I cannot think straight, $\alpha=.89)$.

Coping Styles. To evaluate the personal level of coping strategies the Brief Coping Inventory by Carver (1997) was used, so that with the help of the questionnaire the following dimensions could be differentiated:

Approach Coping (i.e., I've been taking action to try to make the situation better, $\alpha=.79$ ) and Avoidance Coping (i.e., I've been giving up the attempt to cope, $\alpha=.64)$.

\section{PARTICIPANTS}

The study samples consisted of 356 university students from Germany and Sri Lanka. One hundred and forty-nine students of two faculties of the Leipzig of University represented Germany (Faculty of Biosciences, Pharmacy and Psychology and Faculty of Education), while 207 students who studied at the Department of Philosophy and Psychology in the University of Peradeniya and at the Department of Educational Psychology, Faculty of Education in the University of Colombo represented Sri Lanka. The sample included $11.80 \%$ males and $88.20 \%$ female participants. The students came from different stages of their university life: $60.10 \%$ of students were Bachelor students, $1.70 \%$ were Master students and $37.60 \%$ studied Psychology as a side subject to a major in Education. The majority of students were aged between 19 years and 24 years (Germany: $M=21.85, S D=3.78$, Sri Lanka: $M=21.69, S D=2.15)$.

\section{PROCEDURE}

This study was designed using a purposeful sampling method. German students who were studying psychology received credits points by participating in the research. German students of Education were selected by personally visiting the lectures conducted at the Faculty of Education. In Sri Lanka, psychology students were selected from the first year and second year lectures at the Department of Philosophy and Psychology, in the Faculty of Arts, University of Peradeniya. Students of educational psychology were selected from the Department of Educational Psychology, Faculty of Education in the University of Colombo. Each student was given a set of questionnaires which included the four types of scales indicating traumatic experience and its severity and measuring the impact of the events, coping capacity, emotional intelligence and resilience. Subjects agreed to participate anonymously and voluntarily and received written background information on the research.

\section{RESULTS}

Figure 1 shows the different types of traumatic events which the students of our samples experienced. The
Emotional intelligence and resilience: effect on trauma coping 
Asanka Dilan

Nayana

Bulathwatta,

Evelin Witruk, Konrad Reschke following traumatic events were identified throughout the first part of the Essener traumatic event questionnaire (Tagay et al., 2004): Sri Lankan students showed a higher frequency of natural traumatic events than the students from Germany. Other types of traumatic events were more or less similar in each country.

In this summary of hierarchical regression analysis (see Table 1) the predictive value of considered research variables (age, emotional intelligence, trauma symptoms, sense of mastery, emotional reaction) with approach and avoidance coping in both countries is depicted.

Hierarchical multiple regression analysis was conducted in order to test hypothesis 1 (emotional intelligence $\rightarrow$ approach coping).

In Germany emotional intelligence is a good predictor $\left(R^{2}=.37, \beta=-.23, p<.001\right)$ of approach coping strategies. Traumatic symptoms $(\beta=-.21, p=.010)$ and resilience [sense of mastery $(\beta=.37, p<.001)$, and

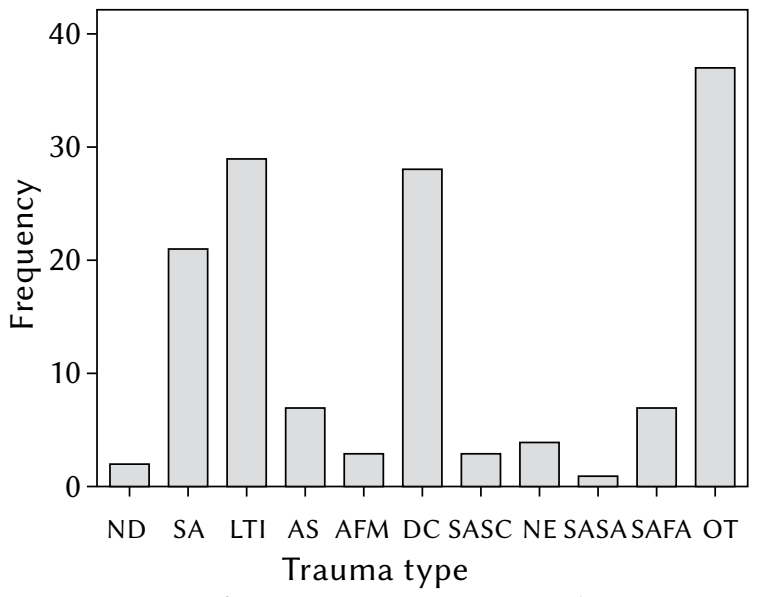

Types of trauma in German students emotional reactions $(\beta=-.39, p<.001)]$ play a role in determining approach as a coping strategy, too.

When we consider the avoidance coping in the German student sample, the situation is rather different from the approach coping. Emotional intelligence is not a good predictor $\left(R^{2}=.18, \beta=.14, p<.001\right)$ of avoidance coping among German students.

Sri Lankan students show the opposite pattern of avoidance and approach coping to the German students. Emotional intelligence is a good predictor together with resilience and traumatic symptoms for avoidance coping $\left(R^{2}=.27, \beta=-.13, p<.001\right)$. Surprisingly, emotional reaction capacity as a subscale of the resilience scale is also a good predictor of determining avoidance coping within the Sri Lankan student sample $(\beta=-.15, p<.001)$.

Emotional intelligence is not a good predictor $\left(R^{2}=.16, p>.001\right)$ of approach coping strategies in Sri Lankan students. However, emotional reaction as

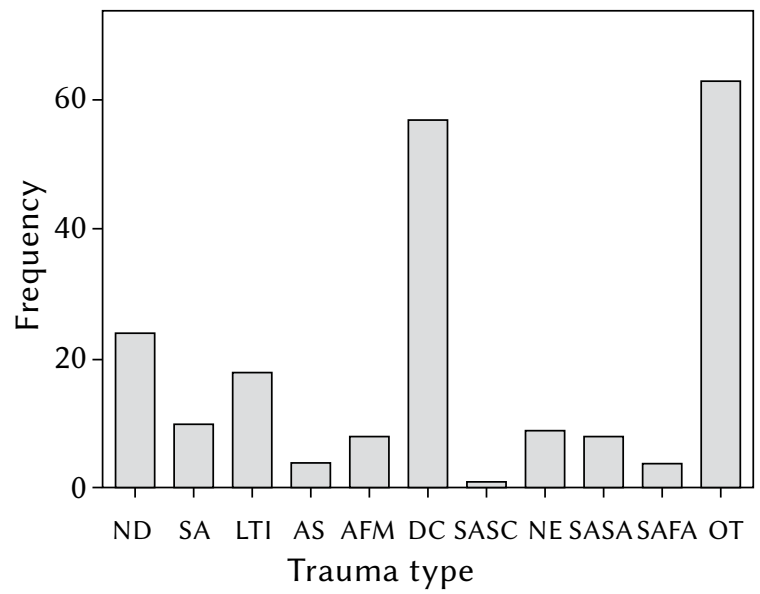

Types of trauma in Sri Lankan students

Note. ND - Natural Disaster, SA - Serious Accident, LTI - Life Threatening Illness, AS - Assault by a Stranger, AFM - Assault by a Family Member, DC - Death of a Close person, SASC - Sexual Abuse by a Stranger as a Child, NE - Neglect, SASA - Sexual Abuse as an Adult, SAFA - Sexual Abuse by a Family member as an Adult, OT - Other Traumatic events.

Figure 1. Prevalence of trauma.

Table 1

Summary of regression analysis

\begin{tabular}{lcccc}
\hline \multirow{2}{*}{ Variables in the regression } & \multicolumn{2}{c}{ Approach coping $(\beta)$} & \multicolumn{2}{c}{ Avoidance coping $(\beta)$} \\
\cline { 2 - 4 } & Germany & Sri Lanka & Germany & Sri Lanka \\
\hline Age & .02 & -.00 & .00 & -.01 \\
Emotional intelligence & $-.23^{* * *}$ & .05 & $.14^{* * *}$ & $-.13^{* * *}$ \\
Trauma symptoms & $-.21^{* *}$ & .22 & .10 & .15 \\
Sense of mastery & $.37^{* * *}$ & -.01 & .15 & -.05 \\
Emotional reaction & $.39^{* * *}$ & $-.22^{* * *}$ & -.20 & $-.22^{* * *}$ \\
Regression summary & $F=13.57^{* * *}$ & $F=8.97$ & $F=5.26$ & $F=11.48$ \\
\hline
\end{tabular}

Note. ${ }^{*} p<.05,{ }^{* *} p<.01,{ }^{* * *} p<.001$ 
resilience capacity has a significant negative impact on approach coping strategies $(\beta=-.22, p<.001)$.

Results of the hierarchical multiple regression revealed that German students use their resilience more frequently, whereas Sri Lankan students use both the emotional intelligence and resilience in order to overcome traumatic experiences; thus $\mathrm{Hy}$ pothesis 1 was partially accepted.

Regarding Hypothesis 2: There is a positive significant correlation of emotional intelligence and resilience after a traumatic event. Results of bivariate correlations indicate that there is only one positive significant relationship between EI dimensions and resilience dimensions among German students: The relationship between optimism (factor of resilience) and emotionality (factor of EI) $(r=.36, p=.010)$ shows a positive significant correlation; thus Hypothesis 2 can be in parts accepted in the German sample.

Surprisingly, in the Sri Lankan student group we found significant positive correlations varying from $r=.45$ to $r=.14$ between aspects of EI (wellbeing, self-control, emotionality, sociability) and the variables of resilience (optimism, self-efficacy, adaptability, sensitivity, recovery, impairment); thus Hypothesis 2 was accepted in the context of Sri Lanka.

Regarding Hypothesis 3: Sri Lankan students show a higher frequency of experiences of manmade trauma (personal) as well as natural traumas in comparison with German students. Ninety-four per cent of the German students and about $89 \%$ of the Sri Lankan students reported personal traumatic experiences in the past. Twenty-two per cent of Sri Lankan students have faced trauma following natural disasters and $2 \%$ of German students have faced trauma after natural disasters. Therefore, Hypothesis 3 is partially accepted: Sri Lankan students show higher frequency of natural trauma and German students show higher frequency of personal traumas.

The following hypotheses were tested using the $t$-test:

Regarding Hypothesis 4 (tendency of using Approach Coping in Sri Lanka and in Germany): The tendency to use approach coping in German students $(M=3.00, S D=0.43)$ was not significantly higher than in the Sri Lankan students $(M=2.93, S D=0.48$, $t=-2.45, p=.230, d=0.06)$. Therefore, Hypothesis 4 can be rejected.

Regarding Hypothesis 5 (level of using avoidance coping): The tendency to use avoidance coping in German students $(M=2.26, S D=0.38)$ was significantly higher than in the Sri Lankan students $(M=2.10, S D=0.35, t=10.00, p<.001, d=0.21)$. Therefore, Hypothesis 5 was not confirmed, because German students show a significantly higher amount of avoidance coping.

Hypothesis 6 (German students' emotional intelligence and Sri Lankan students' emotional intelligence). Emotional intelligence of German students $(M=2.77, S D=0.72, t=-29.02, p<.001)$ is lower than that of Sri Lankan students $(M=4.97, S D=0.69)$; therefore Hypothesis 6 can be rejected.

Finally, Hypothesis 7 regarding the tendency to use resilience capacity in terms of a sense of mastery and emotional reactions was proved right. In the German student sample the sense of mastery $(M=2.81, S D=0.50)$ was significantly lower than in the Sri Lankan student sample $(M=2.93, S D=0.41$, $t=1.20, p=.010, d=0.13)$. But the emotional reaction capacity in German students $(M=2.75, S D=0.49$, $t=4.06, p<.001, d=0.48)$ was significantly higher than in the Sri Lankan student group $(M=2.12$, $S D=0.64)$. Therefore, Hypothesis 7 was partly confirmed. German students had higher values in emotional reactions as part of their resilience with trauma, whereas Sri Lankan students have higher values in sense of mastery with their traumatic events (Table 2).

\section{DISCUSSION}

The results of the present study can be interpreted on the basis of estimated lifetime prevalence of traumatic events and the level of emotional intelligence and resilience in two different countries. First, prevalence
Emotional intelligence and resilience: effect on trauma coping

Table 2

Results of group comparisons (t-test between German and Sri Lankan samples)

\begin{tabular}{lcccccccc}
\hline \multirow{2}{*}{ Research variables } & \multicolumn{2}{c}{ Sri Lanka } & \multicolumn{2}{c}{ Germany } & \multirow{2}{*}{$t$} & \multirow{2}{*}{$p$} & \multirow{2}{*}{$d$} \\
\cline { 2 - 5 } & $M$ & $S D$ & & & & & \\
\hline Traumatic symptoms & 0.98 & 0.45 & 0.55 & 0.50 & -8.35 & $<.001$ & 0.40 \\
Emotional Intelligence & 4.97 & 0.69 & 2.77 & 0.72 & -29.02 & $<.001$ & 0.84 \\
Resilience-I (SOM) & 2.93 & 0.41 & 2.81 & 0.50 & 1.20 & .010 & 0.13 \\
Resilience-II (ER) & 2.12 & 0.64 & 2.75 & 0.49 & 4.06 & $<.001$ & 0.48 \\
Approach Coping & 2.93 & 0.48 & 3.00 & 0.43 & -2.45 & .230 & 0.06 \\
Avoidance Coping & 2.10 & 0.35 & 2.26 & 0.38 & 10.00 & $<.001$ & 0.21 \\
\hline
\end{tabular}

Note. SOM - Sense of Mastery; ER - Emotional Reaction. 
Asanka Dilan

Nayana

Bulathwatta,

Evelin Witruk, Konrad Reschke of trauma did not show a big differences in terms of types of trauma.

This study presented findings that can be effectively interpreted by the research of the Hofstede Center (2015). When considering emotional intelligence as discussed in this research, German students have a lower tendency to use emotional intelligence than the Sri Lankan students. According to Petrides (2010), trait emotional intelligence is a more complex phenomenon the ability emotional intelligence, and it can be defined as a constellation of emotional self-perceptions located at the lower levels of the personality hierarchy. It has certain characteristics such as adaptability, assertiveness, emotional expression, emotional management of self and others, emotional perception of self and others, emotional regulation, impulsiveness, relationships, self-esteem, self-motivation, social awareness, self-management, trait empathy, trait happiness, and trait optimism. Therefore, we can assume differences between Germans and Sri Lankans in the qualities of emotional intelligence. Cultural patterns of collectivism facilitate Sri Lankans so often to engage with society. In order to do that, they need more emotional engagement qualities and some characteristics that facilitate social relationships. These qualities help them to become stronger and acquire skills they can use to understand social phenomena and to manage their relationship within society. Emotional intelligence qualities, which were mentioned earlier, are originated at the individual level and spread into the level of society.

The Sri Lankan society seems to have a higher level of power distance than the German society (The Hofstede Center, 2015). This is determined to a large extent by the hierarchy within the society that may begin with the power hierarchy within a family. But in Germany the hierarchy of the power structure is significantly lower than that of Sri Lanka. This may impact on German students' emotional intelligence and resilience capacity.

When we talk about the hierarchy of factors influencing the determination of coping strategies, hierarchical regression analysis indicates that the impact of emotional intelligence on approach coping among Sri Lankan students is lower than that of German students. Moreover, the German students use their resilience more frequently, whereas Sri Lankans use both the emotional intelligence and resilience in order to overcome traumas frequently. In general, all factors - resilience, approach coping and emotional intelligence - have an impact on the course of trauma among a student population in different ways.

Basically there were no significant differences in terms of trauma between the two countries. The Sri Lankan students showed a higher amount of natural trauma. Moreover, the level of resilience among German students was higher than among Sri Lankan students. The emotional intelligence capacity of
Sri Lankan students is higher than that of German students. Emotional intelligence and resilience predicted German students' avoidance coping capacities, and emotional reaction capacities of Sri Lankan students predicted their avoidance coping capacities.

\section{LIMITATIONS AND SUGGESTIONS FOR FUTURE RESEARCH AND PRACTICES}

The present study has several limitations. First, this research was not based on a random sampling method. Secondly, German students' motivation level to participate in the research might be rather high as they received credit points for their participation. Moreover, the research was conducted with university students who were studying Psychology and Psychology related subjects (Educational Psychology). As a result of that, there was a small number of male participants compared to female participants, because there is a general tendency for the wish to study psychology to be higher in females than males in both countries. Questionnaires used in this research have been developed in the European and American context and were translated and back-translated into the Sri Lankan context. Cultural applicability may also impact on the outcomes, but the cultural impact was not measured with a specific questionnaire. When we consider the Sri Lankan context, due to the prevalence rates of natural trauma, more people from disaster affected areas could have been found. But the research in Sri Lanka was conducted based only in two main cities in Sri Lanka.

Considering suggestions for future studies, research with a longitudinal study also would facilitate the identification of changes of trauma coping for participants. Future research could be conducted at faculties within the university in which more male participants are available. Moreover, further research should be conducted combining quantitative and qualitative approaches.

\section{References}

Agaibi, C. E., \& Wilson, J. (2005). Trauma, PTSD, and resilience: a review of the literature. Trauma, Violence, \& Abuse, 6, 195-216.

American Psychiatric Association. (2013). Diagnostic and Statistical Manual of Mental Disorders: DSM-5 $\left(5^{\text {th }}\right)$. Washington, D.C.: American Psychiatric Association.

Atwoli, L., Stein, D. J., Koenen, K. C., \& McLaughlin, K. A. (2015). Epidemiology of posttraumatic stress disorder: prevalence, correlates and consequences. Current Opinion in Psychiatry, 28, 307-311.

Banyard, V. L., \& Cantor, E. N. (2004). Adjustment to college among trauma survivors: an exploratory 
study of resilience. Journal of College Student Development, 45, 207-221.

Bonanno, G. A. (2004). Loss, trauma, and human resilience: have we underestimated the human capacity to thrive after extremely aversive events? American Psychologist, 59, 20-28.

Bulathwatta, A. (2013). Trauma and coping among university students. exploring emotional intelligence application on coping with trauma. Arbeitstitle-Forum für Leipziger Promovierende, 2, 29-35. Retrieved from http://www.wissens-werk.de/index.php/arbeitstitel/article/viewFile/159/215

Carver, C. S. (1997). You want to measure coping but your protocol's too long: consider the brief COPE. International Journal of Behavioral Medicine, 4, 92-100.

Friedman, M. J., Resick, P. A., Bryant, R. A., Strain, J., Horowitz, M., \& Spiegel, D. (2011). Classification of trauma and stressor-related disorders in DSM-5. Depression and Anxiety, 28, 737-749.

Gerdes, H., \& Mallinckrodt, B. (1994). Emotional, social, and academic adjustment of college students: a longitudinal study of retention. Journal of Counseling \& Development, 72, 281-288.

Lewis, M. A., Granato, H., Blayney, J. A., Lostutter, T.W., \& Kilmer, J. R. (2012). Predictors of hooking up sexual behaviors and emotional reactions among U.S. College students. Archives of Sexual Behavior, $41,1219-1229$.

Lis-Turlejska, M. (2008). Prevalence of traumatic events and posttraumatic stress symptoms in a student sample in Poland. Torture, 18, 12-19.

Mayer, J., \& Salovey, P. (1997). What is Emotional Intelligence? In P. Salovey \& D. J. Sluyter (eds.), Emotional Development and Emotional Intelligence: Educational implications (pp. 3-31). New York: Harper Collins.

McNally, R. (2006). Cognitive abnormalities in post-traumatic stress disorder. Trends in Cognitive Sciences, 10, 271-277.

Perkonigg, A., Kessler, R. C., Storz, S., \& Wittchen, H.-U. (2000). Traumatic events and posttraumatic stress disorder in the community: Prevalence,risk factors and comorbidity. Acta Psychiatrica Scandinavica, 101, 46-59. doi: 10.1034/j.16000447.2000.101001046.x

Petrides, K. (2010). Trait Emotional Intelligence Theory. Industrial and Organizational Psychology, 3, 136-139.

Petrides, K., Frederickson, N., \& Furnham, A. (2004). The role of trait emotional intelligence in academic performance and deviant behavior at school. Personality and Individual Differences, 36, 277-293.

Prince-Embury, S. (2007). Resiliency scales for children and adolescents: A profile of personal strengths ( $1^{\text {st }}$ ed.). San Antonio, TX: Harcourt Assessment. Retrieved from www.PsychCorp.com
Pynoos, R. S. (1993). Traumatic stress and developmental psychopathology in children and adolescents. In R. S. Pynoos (ed.), Posttraumatic stress disorders: A clinical review (pp. 65-98). Lutherville, MD: Sidran Press.

Substance Abuse and Mental Health Services Administration Office of Policy (ed.). (2014). SAMHSA's Concept of Trauma and Guidance for a Trauma-Informed Approach. Rockville, MD: Substance Abuse and Mental Health Services Administration.

Tagay, S., Düllmann, S., \& Senf, W. (2004). Essener Trauma-Inventar, LVR-Klinikum Essen. Essen: Universität Duisburg.

The Hofstede Center. (2015). Sri Lanka and Germany Comparison of cultural dimensions. Retrieved from http://geert-hofstede.com/sri_lanka.html

Vrana, S., \& Lauterbach, D. (1994). Prevalence of traumatic events and post-traumatic psychological symptoms in a nonclinical sample of college students. Journal of Traumatic Stress, 7, 289-302.

Walker, J. (ed.). (2005). Focal Point: Resilience and Recovery. Research and Training Center, Portland.

Wilson, J. P., \& Raphael, B. (1993). International handbook of traumatic stress syndromes. New York, London: Plenum Press.
Emotional intelligence and resilience: effect on trauma coping 